\title{
Francis Skinner's Original Wittgenstein Brown Book Manuscript
}

\author{
Arthur Gibson, Cambridge
}

\section{The Mathematical Association's Wittgenstein Archive of Francis Skinner}

It was an absence continually present with us: did manuscripts dictated by Wittgenstein to Francis Skinner exist?

We can thank the Mathematical Association for their survival. It is important to compliment this august institution for its retention, care, and exemplorary handling, of the Wittgenstein Skinner archive (see Plate 1), as well as its willingness to make the archive available. ${ }^{1}$ Another reason that the Skinner Archive survives is due to Professor R. L. Goodstein's good offices. He was an outstanding, even historic, President of and wise influence in the Mathematical Association with a distinction that enhanced its already considerable reputation.

\section{Wittgenstein, Skinner and Goodstein}

In the early and mid 1930s Wittgenstein, Skinner, and Goodstein had a special triangular, supportive relationship. Goodstein was supervised in his mathematics $\mathrm{PhD}$ research by Wittgenstein. There is a background to add to his presence as an undergraduate in Wittgenstein's lectures, which reveals him to be a victim brave against disadvantage, and with courage to overcome sever obstacles. Perhaps these qualities and his modesty, attracted Wittgenstein.

It would be helpful to have Wittgenstein's correspondence with Goodstein. Instead, we have only one case of Goodstein writing to Witt-

${ }^{1}$ The main credit for the archive's survival and good condition goes to the work over many years of M. Price and M. Walmsley (of the Mathematical Association). The Archive is on loan from the MA to Trinity College Cambridge. 
genstein - thanking him for sending the aforementioned archive, soon after Skinner's death. ${ }^{2}$ Insight into the biographical triangle can be afforded by the following letters sent from Skinner to Wittgenstein ${ }^{3}$ :

Letter [1]

Saturday, 22ND July, 1933.

Dear Ludwig,

On Thursday morning I had a letter from Goodstein. He is having a very hard time now, as it is very hot in London now, and very exhausting sitting in the shop. He was very depressed...We took the train, and spent the afternoon and evening at a fishing village at the mouth of the Thames. He brought his fiancée with him. I think it did both of them good, as the hot weather in London had made things very difficult between them. Everything went alright for them, I think.

Goodstein's fiancée was Goodstein's uncle's wife. His very orthodox Jewish parents had banned Goodstein from being with her. As an undergraduate he was deprived of financial support for this reason.

Letter [2]

17 Sollershott, West,

Letchworth, Herts..

Tuesday, Aug. 22ND.

Dear Ludwig,

I went to London yesterday .... and saw Goodstein for about an hour...I saw Goodstein again in the afternoon and evening. Things had been going slightly better with him. Last time, when I saw him, on Thursday, he looked much more cheerful and happy than earlier in the holidays, but yesterday he seemed anxious and did not look happy. His fiancée left her husband last Wednesday. I think he feels uncertain what she is going to do now, whether she will go back to her husband or not. I had a feeling he didn't quite know what he wanted her to do, and that he was almost relieved that there were difficulties,

${ }^{2}$ For which see McGuinness 2008, letter 295.

3 These are quoted from Wittgenstein 2005 and Brian McGuinness, with all due acknowledgement and thanks. (Variations in orthography attempts to preserve the original writing styles.) 
which might make it necessary for her to return. I think he would be very glad of a letter from you.

I think of you a lot, and how dear and lovely you are to me.

With love,

Letter [3]

5 Sept 1933

...Sunday and Monday. I wanted very much to write to you, but I never felt quiet enough. I was very glad to get your second letter Monday morning. It helped me a lot. While I was in London, Goodstein's affairs became very difficult. I feel afraid he may be doing lots of things in his state of excitement which will really make things harder for him.

His fiancée's husband is in a mad state of anger with him. I was with Goodstein when he went to the house where his fiancée is staying. When he got there, her husband suddenly came out of the front door. He had only just discovered where she was living. He rushed down the steps to the gate of the front garden, and shouted at Goodstein waving his fists at him and threatening him. I don't know whether he would really have attacked Goodstein, but he had already attacked Goodstein's brother, who has practically no connection at all with Goodstein. I felt very depressed after this happened. I think it makes it very hard for Goodstein to do things quietly....

I think of you a great deal.

With love,

Letter [4]

Jan $3^{\text {rd }} 1934$

Francis.

P.S. On Monday evening my Mother received a letter from Goodstein's Uncle saying Goodstein had succeeded in enticing his wife from him and that I was now assisting him, and would she use her influence to stop me. I have never talked about Goodstein's affairs with my parents. I don't think my Mother understands my connection in the matter. She wants me not to talk to Goodstein about this matter any more, at least till his agreement with the College has ended. I have told her I couldn't do this as long as Goodstein himself cared to talk over his affairs with me.

Letter [5]

N FRANCIS SKINNER, 8. 1. [1934] 
As from 17 Sollershott, West,

Letchworth,

Herts..

Monday, Jan 8th

Dear Ludwig,

...

In my last letter I wrote to you that my parents didn't understand my connection in Goodstein's affairs.

I don't seem to be able to say anything about the matter to my Mother which doesn't depress her, partly because she doesn't understand what I am trying to say, but mostly because practically everything I say is so bad and said in such a bad spirit. This makes me depressed too. I don't mean there has been a lot of conversation about it, but the little there has been has generally not gone in the right way. I think of you a lot and I am longing to see you again. If you can say anything about what I have just written, I should be awfully glad to hear it. With love,

Letter [6]

ER, 10. 1. 1934

17 Sollershott, West,

Letchworth,

Herts..

Wednesday, Jan 10th.

Dear Ludwig,

I got back here last night. This morning I had a short conversation with my Mother about my connection with Goodstein's affairs in which everything she said about the matter was very kind and nice. I feel very glad as I hated to go back to Cambridge while there was still a misunderstanding. At present I intend to return to Cambridge Friday, Jan. 12th. I look forward very much to seeing you again. I think of you a lot.

With love,

Letter [7]

\author{
N. 2. Great Court, \\ Trinity College, \\ Cambridge. \\ Thursday, Mar. 22ND. \\ Dear Ludwig,
}


I miss you terribly here in Cambridge...The telegram we sent to Hutt did not reach him... I spent most of Monday and also Tuesday morning trying to find Goodstein in London. I have sent a letter to Hutt in Munich asking him to write me Goodstein's address. I am very sorry I haven't yet been able to have a talk with Goodstein. ... With love,

Francis.

Goodstein was friends with Hutt, and in later years he and his family sometimes visited Hutt; but when Hutt, long after Wittgenstein's death, wrote a contribution to the public debate about the claim that Wittgenstein was homosexual, Goodstein refused to have any contact with him.

Letter [8]

25. 3.1934

N. 2. Great Court,

Trinity College,

Cambridge.

Sunday, March 25th.

Dear Ludwig,

...

I haven't yet got Goodstein's address. I had a conversation with my Mother today. I didn't manage to make my Mother understand why it was impossible that I should allow my parents to come in any way between myself and Goodstein. I think of you a great deal.

With love,

We already knew that at least some of Skinner's family opposed Wittgenstein's influence on Skinner's (lack of) career. Letter [8] shows that only a temporary respite was signalled by Letter [6]. The tense dynamics reported in Letters [4] and [5] continued between some of Goodstein's and Skinner's families. It may also help explain why Goodstein's remarks directed at Skinner family, in his reply to Wittgenstein about the archive (in McGuiness, 208: Letter 295) are so terse and dismissive of Skinner's family.

Letter [9]:

SKINNER, 4. 4. [1934]

17 Sollershott, West, 
Letchworth,

Herts.

Wednesday, April 4th.

Dear Ludwig,

I got your letter last Wednesday evening. I was very glad to get it. Later in the evening I had a letter from Hutt. I had told Hutt roughly what I wanted to write to Goodstein about and why I wanted his address. Hutt said he was writing to Goodstein and would tell him that I wanted to see him, but he said he would not like to give me an address if for some reason it was better kept unknown. ...

When I got back here on Friday, I found a letter from Goodstein. Goodstein wrote me a very nice letter and gave me his address. On Saturday I wrote him about everything I wanted to say to him. I didn't finish the letter till yesterday...

With love,

\section{Letter [10]}

S SKINNER, 8. 4. 1934

Isle of Portland.

Sunday, April 8th.

Dear Ludwig,

...When I got back [to Cambridge] I found a letter from Goodstein waiting for me. Goodstein wrote that he had failed to get the job at Hull and was beginning to feel very desperate about a job. He said that his fiancée thought that the best thing if he didn't get a job was to find a shop for her and for him to go back to Cambridge for a year. Later on in the letter he wrote that another idea of his fiancée[']s was that he should work next year for the Civil Service and that in any case she thought another year at Cambridge would improve his chances of a job. He said that he did not believe they would have him back at Cambridge but that could easily be tried. He said he certainly did not care for such a solution even though it was so temporary: it seemed like putting off all the difficulties for yet another year. He said he'd be awfully glad if I could offer some suggestion. I find it very hard to know what I should write him. I feel if I could see him and could find out exactly how he felt about the matter, then I might know what to say. I don't like the idea of his trying for the Civil Service as I don't feel that is at all the right kind of life for him. Also I think there would be lots of other difficulties for him if he tries to do that. I also don't know what I feel about his being at Cambridge another year. Before he left Cambridge I had felt it might be a very good thing. But now I feel it might be 
in a sense making a step back and therefore might not be good for him. I feel I could judge all this much better if I saw him. Though upset about not getting the job, I thought on the whole Goodstein seemed happy from his letter. I feel if things are going well between him and her it might be better not to break this up... I was glad to leave Cambridge as I didn't feel able to work there at all... Thank you for everything. I hoped very much your work with Waismann would go off well...

\section{Letter [11]}

August 111934

Saturday, Aug.11th

Dear Ludwig, ...

I have had another letter from Goodstein. I felt from his letter that he seemed to be feeling some sort of unhappiness. He seemed to me discontented in a way. He is also depressed at not being able to get a job. He is very anxious to see me. I think I shall go to see him either next Tuesday or Wednesday.

\section{Letter [12]}

Overdale, Cock's Hill,

Perranporth,

Cornwall.

Wednesday, Aug. 22ND.

Dear Ludwig, ...

I didn't tell you in my last letter that Hutt is also staying here with Goodstein. It has been very nice seeing him again. He seems to me very well. I think also he is feeling more happy and confident about his work next year. I think he cares about it very seriously. Goodstein hasn't yet got a job. I feel very sorry as he definitely looked forward to teaching and now feels very disappointed. I don't think at present he cares about the idea of going in for a shop. If he doesn't feel cheerful about the idea of a shop, I don't think it will be the right thing for him. Goodstein himself also thought the idea of the Civil Service absurd. I told him what you thought. I also think he realises that he probably wouldn't be able to go back to Cambridge with her. Hutt thinks they certainly wouldn't have him. I feel things will be very hard for Goodstein. I wish he had had better luck. 
...Goodstein is very kind to me. I enjoy very much doing housework and cooking with Goodstein and Hutt. I think it does me good and gives me a rest. I think about you a great deal.

With love,

Letter $[13]^{4}$

17 Sollershott, West, Letchworth, Herts.

Sept.17th Tuesday.

Dear Ludwig,

It was very lovely to get your letter today from Leningrad... I have just heard from Goodstein that he has got a job at Reading University. I think the position is rather a good one - senior lecturer in pure mathematics. He said the people there were very kind and considerate to him in his interview. I am very glad that he has at last got some security and that it's a good job. I think it may be a very good job for him. It is only a small University, so I suppose he will only have to teach (or mostly at any rate) elementary work. I think he will do that very well and his pupils will find him very stimulating. I hope it goes well. I shall miss him a lot next year at Cambridge. He was always very kind to me and always welcomed me when I went to see him. I depend on friendly intercourse of this sort such a lot. I can't help feeling sad he won't be there, although I know this is selfish. I think a lot about the work which we are going to do next year. I feel that the spirit of the method which you used last year is so good.

Everything, I feel, is absolutely simple and yet its all full of light. I feel it will be very good to go on with it and get it ready in some form for publication. I feel that the method is so valuable. I hope very much we shall be able to get on with it. We will do our best. I'd like to say again that I hope you will stay longer in Moscow than the time you arranged for if you feel there is any chance that you might learn more. It would be valuable for both of us. I was very glad to get both your letters. I think of you a great deal and hope that you are feeling well.

W. 1.

Ray Monk rightly regards the 'work' and 'it' in Letter [13] as a reference to the emergent Brown Book. In the letter there is no presumption of authorship on Skinner part. Rather, he appears to presuppose unity of purpose

\footnotetext{
${ }^{4}$ A Skinner bearing on this appointment is to be found in the Appendix.
} 
and activity. This was the blend that served Wittgenstein: identities in symmetry and unity subservient to the creative purpose.

\section{The Archive}

The contents are described and published - with one exception - in the forthcoming publication Dictating Philosophy. The manuscripts are comprised of:

Add.ms.a.407/1: 'PINK BOOK' (SUCCESSOR TO THE 'YELLOW BOOK')

Add.ms.a.407/2: 'COMMUNICATION OF PERSONAL EXPERIENCE' Add.ms.a.407/3: 'PHILOSOPHY - COURSE OF LECTURES'

Add.ms.a.407/4: 'VISUAL IMAGE IN HIS BRAIN'

Add.ms.a.407/5: 'THE NORWEGIAN NOTEBOOK'

Add.ms.a.407/6: 'SELF-EVIDENCE AND LOGIC'

Add.ms.a.407/7: 'NEW BROWN BOOK'

Add.ms.a.407/8: 'MATHEMATICAL INVESTIGATIONS'

Since the edition Dictating Philosophy [forthcoming] publishes with all but one of these manuscripts - i.e., 'Add.ms.a.407/8' - and this manuscript is being prepared as a new edition of the Brown Book, I will restrict attention here to a few facets of Skinner's Wittgenstein Brown Book's manuscript.

\section{Wittgenstein's Brown Book}

Until the discovery of the Wittgenstein Skinner Archive, there appeared to be no original manuscript or first-generation copy of the Brown Book. There seemed only to be a later generation carbon - the Von Wright carbon copy in Trinity College Library. It may be that there were some manuscript(s) of the first generation, apart from Skinner's, for example in Rhees's a portion of now partly auctioned and partially dispersed as well as unpublished and uncatalogued papers, in some anonymous ownership. So the first and only handwritten copy of the Brown Book is in the Archive. Page 1 of the manuscript is typical in that Wittgenstein has written new expressions that have no parallel in the Rhess published version (see Plate 2). 
The Brown Book manuscript comprises of five foolscap exercise books, in brown, buff and pink. This Skinner Brown Book is replete with Wittgenstein's own handwritten revisions and additions to it, which frequently differ from the published and other printed versions. Wittgenstein's handwriting adds material in the form of new phrasing, sentences, and even paragraphs. Sometimes he corrects, revises, or adds to Skinner's handwritten version. ${ }^{5}$ Such corrections are strong evidence of the need for a new edition of the Brown Book. Some of the Skinner readings differ from the published version, and are not corrected by Wittgenstein, it could be that Ambrose's version (if there were one) was not informed by Skinner's manuscript, or not in Part II. ${ }^{6}$

That Skinner's Brown Book attracts should attract further enquiry is illustrated by Skinner Book III, p, 20, which parallels the published Brown Book p.135. In the Skinner version on the page facing p.135 there is a paragraph in Wittgenstein's handwriting, which parallels paragraph two of the published version (the German related to Philosophische Untersuchungen August 1936, p.118.); yet this latter German is not identical to the English version. It also seems that Wittgenstein has deleted the phrase "an explanation", which is in the printed version. This leaves in Skinner's text the reading "proposition", which may indicate Wittgenstein prefers that to the (printed?) version he knew. This is typical of many other changes from the published text.

There are instructions in the manuscript that readily read as instructions to a printer for publication. So, for example, we find in manuscript Book II, Remark $\S 64$ that the instruction "new line" is written above the

${ }^{5}$ Sometimes here smaller changes have some importance: at the bottom of page 1 of the Skinner manuscript Wittgenstein appears to have deleted "Note:", which is "Note." in Skinner. This has the effect of restoring the following word "Objection:" to a stronger narrative role. This is typical of numerous changes of detail by Witttgenstein.

${ }^{6}$ Questions abound here, ones that I would like to pursue while preparing a new edition. For example, may it be that the text written in Wittgenstein's hand-writing in the Skinner manuscript betray a different route of emergence for the copy which Wittgenstein later intended to be the authoritative version of the Brown Book This may questionably presuppose Wittgenstein entertained such a division of significance about order when he moved on to earlier formulations of the PI? 
top line (commencing " Let us ask the question:..."), at the head of the page, to indicate that this line does not run on from the last sentence of the previous page.

\section{An extension to the published Brown Book}

There is an important issue that arises when contrasting the published ending of the Brown Book and Skinner's manuscript. The page where the published Brown Book text ends, in the corresponding point in Skinner's manuscript, the following unwieldy expression occurs (see Plate 3):

"ended here the printed version" [sic].

First, this comment is written in pencil, such pencil writing as Wittgenstein used in his writing everywhere else in all the Skinner manuscripts. It does not quite seem certain to be Wittgenstein's writing, though it might be. It is such a short expression, and in small handwriting that here might be some doubt about this attribution. Yet the writing of the "of" sees clearly and ringed in pencil is characteristically Wittgenstein's. The unusual style of the letters: 'd', 'f', 'p' and ' $t$ ', and can be seen in various examples in the Appendices and throughout his manuscripts. ${ }^{7}$

Secondly, could the quoted expression, "ended here the printed version", be construed as the result of tired English literalising and betraying a German (Austrian) inner voice: "Hier ist geended".

Thirdly, the expression "printed version" might indicate either a cyclostyled, carbon copy, or even 'published' or a typed version. Is it feasible to consider that the expression "ended the printed version" presupposes there was another version - i.e., one with the next 28 pages that follow the ending of Rhees's published late version, which appears in Skinner manuscripts Book V and through Book VI. Both of these are bound, coloured and marked, in much the same way as are the other Skinner exercise

${ }^{7}$ Wittgenstein varied his style somewhat, particularly in relation to three sorts of size of writing he used, though the examples above appear to be typical of all three styles.

${ }^{8}$ I have checked the handwriting of other like people and it is certainly not any of the following: Ambrose, Masterman, MacDonald, Anscombe, Geach, Goodstein, Lewy, Moore, Denis Paul, Rhees, Skinner, von Wright, and Wisdom. 
Books (I to IV) that make up his Brown Book. In physical form and colour they are also parallel with the large ' $\mathrm{C}$ ' exercise lecture books series written throughout in Wittgenstein's handwriting, which cover the same period as the Blue and Brown Books.

The last page of the Brown Book in Skinner's manuscript is, over the next page, succeeded by a 28 page sequence, which in its entirety is not in any other version. This is listed above as 'Add.ms.a.407/2' entitled 'COMMUNICATION OF PERSONAL EXPERIENCE'. It also cites some numbers attached to remarks in the Brown Book, thus binding the two manuscripts together in some was as yet to be ascertained. (See Plate 4 for the first page of this extension to the Brown Book.)

\section{Dictation}

In his tenure of the Senior Research Fellowship in Trinity, Wittgenstein was required to lecture in English. For him this quickly became dictation aimed at composing books.

Wittgenstein needed amanuenses who were in unity with his mental and oral states, much as an amanuensis for an ailing composer. So the audience body-count rose quickly, and the audience fell away - to two, while Goodstein wended his way to Reading.

Only once in the Brown Book does Wittgenstein mention 'dictation' (in Remark 66). Within a few lines, unusually, Skinner is in a frenzy of revision, as if Wittgenstein hangs over him like Beethoven scratching out a dedication to a fake empress of words (see Plate 5). Miss Ambrose did not care to be a pianola. She could not learn to understand. Perhaps at this point she left for Moore. She may have claimed that dictation of the Brown Book ceased forthwith when she made an exit. Contrariwise, the Brown Book was finished in her absence. Only Skinner was left, living, as one, within Wittgenstein's will - at home in dictation, on East Road where it seems much of the Skinner archive was finalised with Wittgenstein.

It was only later, that Wittgenstein, in his diary, wished Skinner dead (whilst immediately rueing it), and Skinner's body complied. The period of dictation had ended as Wittgenstein absorbed the act of amanuensis into his being, at some cost to Skinner. Goodstein was a distant intimate, yet bounded to this union, silently holding Skinner's archival heart to and 
within himself - silent about it to the death: unable to impart it to its republic, engulfed as he was in a Tractatus chess ending. (See Plate 6.)

\section{Literature}

McGuinness, Brian 2008: Wittgenstein in Cambridge. Oxford: Blackwell.

Wittgenstein, Ludwig 2005: Gesamtbriefwechsel. Charlottesville, VA: InteLex. Internet-resource, url: http://library.nlx.com (2010/05/06).

\section{Appendix}

Letter [13] refers to Goodstein's securing a post at Reading University. Wittgenstein was a referee, and the following letter indicates other attempts at assistance:

Letter [14]

[25. 9. 1934]

Monday morning.

Dear Ludwig,

I have just got your letter about Goodstein. The only good Mathematical Testimonial he can get is from Ramsey. ...I thought your testimonial could tell them that you thought he would be very keen on explaining things thoroughly to his pupils, and would be good at teaching elementary subjects. I suggested he should get a testimonial from Ursell... I also suggested Verblunsky, but Goodstein did not seem very keen. ...He has a letter from Littlewood who only says that he attended a course of his lectures and that he read the answers to his questions in the Tripos. I also suggested Besicovitch, as Goodstein had attended a lot of his lectures. But Goodstein preferred Littlewood, as he had not answered any of Besicovitch's questions in the Tripos. ..Ramsey has given him a very good testimonial. (so Goodstein writes me) - I am very sorry I can't be with you on the 4th of October. ...

Thank you for everything.

With love, 


\section{Illustrations}

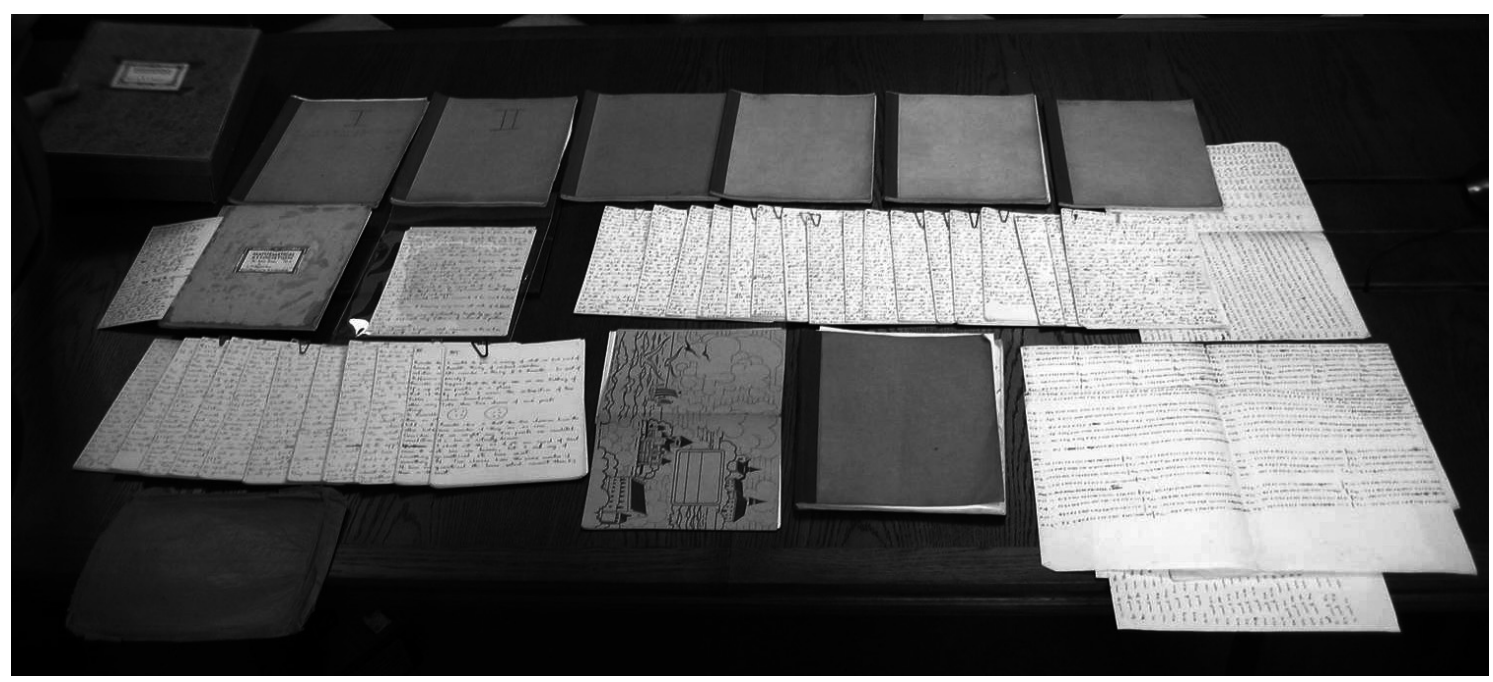

Plate 1. Wittgenstein Skinner Archives.

Angustimis description of how he learut the use of words

He says that he was tanght to speak by learming the names of things. It is clear that whe says this thaiks has in mind the way in which a child learms such wrisds as "man" "sugar "Table".

He does not primarily think of such words as "today". "not", "bnt", perchaps"

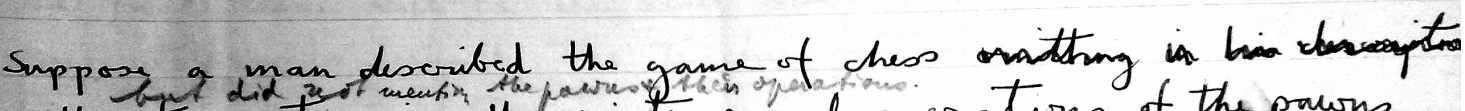
without mentirning the existence and operations of the pawns. His desoription of the game as a natural prenomenon will be incomplete. On the other hand, we may say, he has, complete

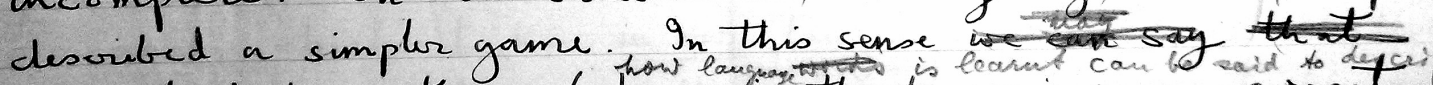

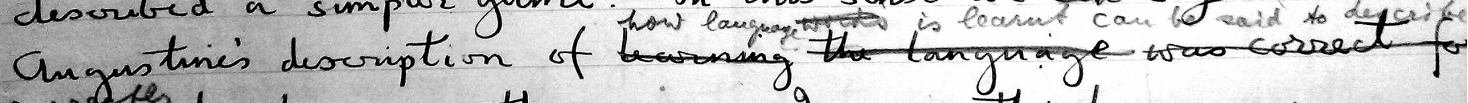
varrompler language than owis. Imagine this language:

1. It function is the communication between a builder ${ }^{A}$ and hi mgax B. B has to haudh \# building stones. These are cube, bire plates becums insed ed columas. The language consists of the

Plate 2. Brown Book page 1 with Wittgenstein revisions. 


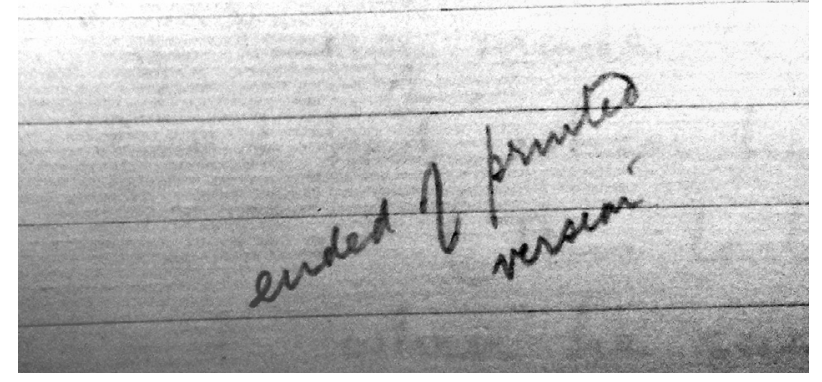

Plate 3. End of Brown Book.

Communication of personal experience

B looks at traffic lights and reports to A what colour shows by calling ont to him alternately the words "red" "green" "yellow". B was trained by bing made to observe the lights while the instructor said"red "when he saw red. "green" when he saw green, tc. (This Last sentence opposes the instructoris saying" red" when he saw red to, say, his saying "rouge" or "moo" when he saw red. The sentence therefore did not say "The instructor told the pupil what he sow as op posed to telling him a lie is ') The condition for B's learning the S.e., had B not reacted by saying the words, or reacted by saying them 'at random', the game world not have come off. I am assuming that B after sometraining in every case said the word the teacher wished him to say (the word which the teacher himself woold have said). Isnit this a case of the communication of personal experience?

as No1. After B has passed the training, we let him look at the traffic lights through various Kinds of media. Whenever he looks through the me duim $\alpha$, he says" red" when without the medium he says "green;, and vice versa. Other media produce other regular changes of this soit im hio reation lout not in the normal person. The question arises: "If he looks thro" the medium so-and-so, does he see what we see or

Plate 4. New Extension to Brown Book. 
a clear case of certain actions, thase of the hammers of the piano being guided by the patteren of the holes in the pianola We could use the expression "the pianola is reading off the record made by the perforations in the roll" and wire might call pattren of such perforations comploc signs or sentences, opporeate th ninidan doasioss opposing their function in a pianola to the function which similar devices have in mechanuszes of a different type, caposibar lock the movoment of a bolt is caused by a patimh de not say the bot was grided by these the idea of bere the connection between the bing guided and the idea of being Nable to read new combinations of signsinm for we should say that the pianola can read any pattirn of per forativins of a particular Kind, is not binlt for one partionlar tune or an set of Ntunes (like a musical box ), whereas the bott

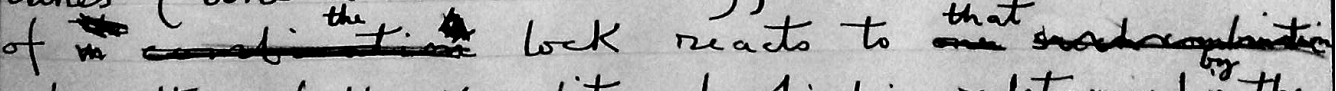
mattern of the Key-lit only which is predetermined in the -(attinative)

E.g. the combination of notches and teeth which form tilt a Key-bit. The bott of a lock is caused to slide by this particular combination. But we should not say that the movement of the bott was guided by the wry in which we tecth and notches 1, 6 . we should not say that the lit moved aceording

Plate 5. Remark 66.

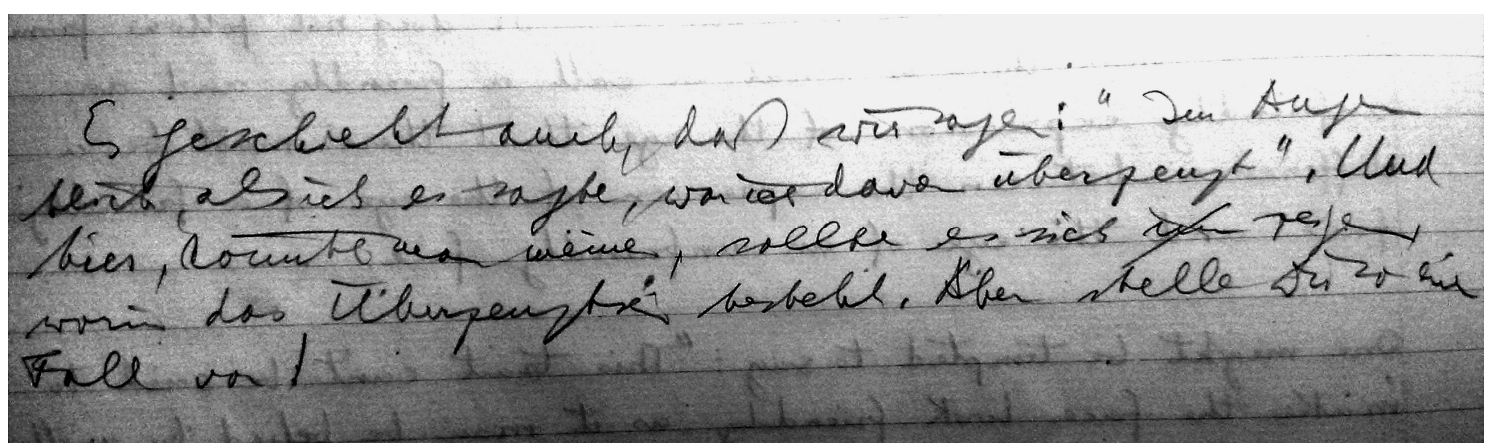

Plate 6. Wittgenstein's German aimed at Brown Book Part 2 Rem 7. 